\title{
JUICIO, DEPOSICIÓN Y OCCISIÓN DEL TIRANO EN FRANCISCO SUÁREZ*
}

\section{IMPEACHMENT AND VIOLENT DEATH OF THE TYRANT IN FRANCISCO SUÁREZ}

\author{
PABLO FONT OPORTO \\ Universidad Loyola Andalucía
}

Recibido: 27/072018 Aceptado: 26/09/2018

\section{RESUMEN}

En el marco de las medidas posibles para frenar al tirano, Suárez señala la del sometimiento legítimo de este a juicio de deposición, bien por parte de la propia comunidad política, bien por parte del Papa (siempre que aquel sea cristiano). Además, Suárez propone para el tirano condenado por juez legítimo un tratamiento especial que supone la ampliación de las posibilidades de occisión legitima del mismo. En todo caso, en términos estrictos, la ejecución de la sentencia (que puede conllevar, en determinadas circunstancias la muerte del tirano condenado) debe corresponder a priori al que la dictó o a aquellos en que el mismo delegue.

Palabras clave: tiranicidio, tiranía, derecho de resistencia, poder directo e indirecto del Papa, juicio del tirano.

${ }^{*}$ Este trabajo se enmarca dentro del Proyecto I+D+I «Pensamiento y tradición jesuita y su influencia en la Modernidad desde las perspectivas de la Historia, la Traductología y la Filosofía Jurídica, Moral y Política» (PEMOSJ), financiado por el Ministerio de Economía y Competitividad del Gobierno de España y el Fondo Europeo de Desarrollo Regional (MINECO/FEDER) (referencia FFI2015-64451-R), y cuyo investigador principal es el Prof. Dr. Juan Antonio Senent de Frutos. 


\section{ABSTRACT}

Francisco Suárez provided a series of measures to stop the tyranny. One of them is the possibility of impeaching the tyrant, which can be either done by the political community or the Pope (if the tyrant is Christian). Furthermore, once condemned by a rightful judge, Suárez proposed a special treatment for that tyrant, which supposed more possibilities of legitimate tyrannicide. In any case, in strict terms, the carrying out of the execution of the sentence (that may involve, in certain circumstances, the death of the condemned tyrant) must correspond a priori to he who dictated the sentence or to those who he delegated to.

Keywords: tyrannicide, tyranny, right of resistance, Pope's direct and indirect power, impeachment of the tyrant

\section{INTRODUCCIÓN}

Francisco Suárez elabora una batería de propuestas y medidas defensivas frente a todo tipo de tiranía. Si bien la gran mayoría de aquellas están poco institucionalizadas (así, el tiranicidio a manos de particulares, o la desobediencia y la resistencia civiles), el profesor jesuita advierte de la posibilidad de que el tirano (ya sea un mal gobernante o un usurpador, pero con especial atención al primero, que goza a priori de cierta legitimidad) sea juzgado y depuesto por quien tiene la legítima potestad para ello, en concreto, la comunidad política y el Papa. El propósito de este artículo es analizar la fundamentación que Suárez lleva a cabo de la posibilidad de dicho enjuiciamiento, así como de las consecuencias de la condena de deposición y los términos en que se produce la ejecución de la misma.

\section{CONTEXTOS Y PRETEXTOS}

\section{CONTEXTO HISTÓRICO Y BIBLIOGRÁFICO}

Si bien Suárez ya había abordado tangencialmente el tema del derecho de resistencia y el tiranicidio en diferentes obras de sus primeras etapas, lo examina con más detenimiento en sus dos tratados de filosofía política de madurez, $D e-$ fensio fidei (en adelante, $D F$ ) y De legibus. Este segundo es un tratado sistemático meditado largamente en el que aborda todo lo relativo a la ley humana, divina y natural. En este trabajo, sin embargo, nos centraremos en la $D F^{1}$. Es

1 Defensio fidei catholicae et apostolicae adversus anglicanae sectae errores, cum responsione ad 
esta una obra de circunstancias, cuya redacción se enmarca dentro de una polémica académica alimentada por un conflicto político-religioso: el del juramento de fidelidad que el rey Jacobo I de Inglaterra había impuesto a sus súbditos, cuyo tenor suponía el reconocimiento de poderes espirituales al primero y la negación de la sumisión del monarca al poder papal. La respuesta por parte de la Iglesia a dicho juramento diseñado expresamente contra los católicos da origen a una disputa en el contexto de la cual Suárez recibe el encargo papal de terciar con una nueva y más mesurada respuesta ${ }^{2}$.

\section{EL CONTEXTO TEÓRICO. LA TEORÍA GENERAL DEL TIRANICIDIO Y LA RE-} SISTENCIA EN SUÁREZ

Suárez desarrolla el núcleo de sus ideas sobre la resistencia civil y el tiranicidio en el capítulo IV del Libro VI de la $D F$ utilizando como base la distinción clásica entre los dos tipos de tirano: mal gobernante y usurpador. En particular, los principios generales de su teoría se encuentran en los §s 1-9 de dicho capítulo. Suárez considera que nadie puede por su propia y particular autoridad matar lícitamente al tirano en razón de su mal gobierno. Esta norma general sólo sufre excepción en el caso de legítima defensa de la vida e integridad física propias o de los miembros de la comunidad. Sin embargo, al tirano usurpador puede matarlo cualquier persona privada miembro de la comunidad que sea víctima de la tiranía, si bien deben cumplirse una serie de condiciones ${ }^{3}$.

apologiam pro iuramento fidelitatis et praefationem monitoriam serenissimi Iacobi Angliae regis. Authore P. D. Francisco Suario Granatensi e Societate Iesu. Conimbricae: apud Didacum Gomez de Loureyro academiae typographum, 1613. Se ha manejado principalmente la edición del Consejo Superior de Investigaciones Científicas en su colección Corpus Hispanorum De Pace. En concreto, para el Libro III: F. Suárez, Defensio fidei III. Principatus politicus o la soberanía popular (Consejo Superior de Investigaciones Científicas, Madrid, 1965). Y para el Libro VI: F. Suárez, De Iuramento Fidelitatis. Documentación fundamental (Consejo Superior de Investigaciones Científicas, Madrid, 1978). Subsidiariamente, se ha utilizado esta edición: F. Suárez, Defensa de la fe católica y apostólica contra los errores del anglicanismo, vol. 4/4, (Instituto de Estudios Políticos, Madrid, 1971). Dichas traducciones han sido modificadas cuando se ha estimado necesario.

2 Sobre el contexto del juramento y el encargo a Suárez vid. Pablo Font Oporto. "Límites de la legitimidad del poder político y resistencia civil en Francisco Suárez" ( $\mathrm{PhD}$ diss., Universidad de Sevilla, 2014), capítulo 2. Consultado el 11 de agosto 2019. https://idus.us.es/xmlui/handle/11441/70443

3 De entre dichas condiciones interesa ahora destacar la primera: que no quepa interponer recurso ante un superior que juzgue al usurpador ( $D F, \mathrm{VI}, \mathrm{IV}, 8)$.

Un desarrollo más extenso de estas cuestiones puede encontrarse en Pablo Font Oporto, El derecho de resistencia civil en Francisco Suárez: Virtualidades actuales (Granada: Comares, 2018), 90-113; Pablo Font Oporto, "El núcleo de la doctrina de Francisco Suárez sobre la resistencia y el tiranicidio", Pensamiento: Revista de investigación e información filosófica 69 (2013): 493-521; Font Oporto, Limites de la legitimidad, capítulo cuarto. 
Por otro lado, en contradicción con esta norma general sobre el usurpador (§s 7-9), en el $§ 13$ Suárez sostiene que tanto el rey legítimo que gobierna tiránicamente como el usurpador pueden ser muertos por un particular sólo en caso de legítima defensa (ya sea autodefensa propia o de la comunidad). Y esto sobre la base de que se considera que el título de legítima defensa confiere a ese particular autoridad pública, pues no es admisible que actúe sin la misma. Ahora bien, la diferencia en la práctica entre ambos tipos de tirano estriba en que en el supuesto del usurpador se considera que cualquier atentado contra este último siempre puede justificarse sobre la base del título de legítima defensa, al entenderse que, debido a su falta de título legítimo para el ejercicio del poder, dicho tirano está permanentemente agrediendo a la comunidad ${ }^{4}$. Circunstancia que no puede presuponerse en el caso del mal gobernante.

\section{EL CASO DEL JUICIO DE DEPOSICIÓN DEL TIRANO}

Para Suárez el supuesto concreto del juicio del tirano y la situación del tirano juzgado y depuesto merecen un tratamiento especial. En efecto, en $D F$ VI, IV, 14-19 afronta de modo particular el examen de estas cuestiones.

1. LA DEPOSICIÓN JUDICIAL DEL TIRANO Y SUS EFECTOS EN LA VALORACIÓN DEL TIRANICIDIO: AMPLIACIÓN DE LA LEGITIMACIÓN $(D F, \mathrm{VI}, \mathrm{IV}, 14)$

1.1. El supuesto del rey mal gobernante depuesto mediante sentencia, excepción a la norma general sobre la licitud del tiranicidio

Observa Suárez que

se sigue de la última explicación referente al tirano propiamente dicho ["proprio tyranno», es decir, el usurpador], que la solución dada anteriormente [en los §s 3-6] con relación al rey [legítimo] que gobierna tiránicamente [esto es, el mal gobernante] es aplicable solamente antes de que se dicte sentencia de deposición contra tal rey, pero no después» ${ }^{5}(D F, \mathrm{VI}, \mathrm{IV}, 14)$.

4 Para Suárez el usurpador es "un enemigo de la comunidad política» ( $D F$, VI IV, 7). La contradicción apuntada entre el $\S 13$ y los $\S \mathrm{s}$ 7-9 ha sido analizada en Pablo Font Oporto, "Tipos de tirano y resistencia en Francisco Suárez”, Anales de la Cátedra Francisco Suárez 51 (2017): 183-207.

5 Cabe advertir que Suárez se refiere aquí a la necesidad de obrar contra todo tirano siempre en ejercicio de autoridad pública, que en el caso del mal gobernante (y salvo el supuesto de legítima defensa) requiere su deposición por el juez competente). Por otra parte, nótese que la acotación "[legítimo]» es del traductor de la edición del Consejo Superior de Investigaciones Científicas. 
Es decir, que la norma general que regula los casos en que es lícito el magnicidio del tirano con título legítimo sólo es aplicable si no se le ha depuesto previamente mediante sentencia de juez legítimo. En otras palabras, la norma general que restringe la licitud del tiranicidio del rey mal gobernante a los supuestos de legítima defensa de la vida propia y de la comunidad decae tras la deposición judicial de dicho rey. Y por tanto se abre en este supuesto la puerta al reconocimiento de la legitimidad de la occisión de dicho monarca en otras circunstancias.

\subsection{Fundamentos de la inaplicabilidad de la norma general al caso del rey} tirano depuesto, así como de la legitimidad de la occisión del mismo

Veamos con detalle los tres fundamentos en los que Suárez asienta esta afirmación del § 14.

En primer lugar, el Concilio de Constanza. En efecto, Suárez se ve permanente obligado a dialogar con los documentos aprobados en dicho concilio, en los cuales se rechaza la legitimidad del tiranicidio en general mediante la condena de algunas de las doctrinas que circulaban en la época. Sin embargo, al igual que en otros pasajes, Suárez encuentra situaciones no contempladas en la condena general del tiranicidio que el Concilio realiza. De este modo, y en este punto concreto, el profesor jesuita sostiene que dicho Concilio "únicamente» condenó la tesis de que es licito matar "al príncipe tirano con autoridad privada sin esperar la sentencia o mandato de juez alguno». Por tanto,

si el juez legítimo de ese rey, cualquiera que sea o pueda serlo, ha dictado contra él una sentencia justa por la que automáticamente le ha depuesto de su trono, ya no es aplicable la declaración del Concilio

(por cuanto dicha declaración rechaza precisamente un texto que lo que afirmaba era la licitud de la occisión del tirano "sin esperar la sentencia o mandato de juez alguno»; vid. DF, VI, IV, 3$)^{6}$.

En segundo lugar, Suárez alega como segundo argumento de su afirmación sobre la inaplicabilidad de la norma general al caso del tyranno in regimine depuesto que cuando

6 De este modo, parece que dejaría de ser ilegítimo el tiranicidio de dicho rey mal gobernante que ha sido depuesto en sentencia justa por juez competente. Sobre el Concilio de Constanza y la interpretación de DF, VI, IV, 3, vid. Font Oporto, El derecho de resistencia, 91-96; Font Oporto, "El núcleo"; Font Oporto, Límites de la legitimidad, capítulo 2. Sobre las continuas referencias de Suárez al Concilio de Constanza y su diálogo con el mismo en la cuestión del tiranicidio, vid. Font Oporto, Pablo. "Tipos de tirano", 186. 
se ha esperado a la sentencia justa y legítima [...], el que mata al tirano [“aggresor»)] no actúa con autoridad privada sino en virtud de la sentencia y, por consiguiente, como instrumento de la autoridad pública ${ }^{7}$ ( $D F$, VI, IV, 14).

En tercer lugar, como último argumento se afirma que "finalmente, una vez que el rey ha sido legalmente depuesto, ya no es ni rey ni soberano legítimo» ${ }^{8}$. Y agrega Suárez:

es más, si después de su legítima deposición continúa ese rey en su obstinación y por la fuerza retiene el poder real ["regnum»], empieza a ser un tirano con relación a su título [“tyrannus in titulo»], ya que no es rey legítimo ni está en posesión del reino con título justo ${ }^{9}(D F, \mathrm{VI}, \mathrm{IV}, 14)$.

\subsection{Transmutación de la tipología del tirano. La consiguiente emergencia} de las normas generales sobre el tiranicidio

Cabe colegir de esa tercera y última aseveración de Suárez que, en el caso de la muerte dada al príncipe destituido que se aferra sin embargo de manera ilegítima al poder, no se aplica la norma general correspondiente al supuesto de la occisión del tirano con título legítimo. Esto es así porque la sentencia de deposición supone en el fondo una transformación en la tipología del tirano, lo que paralelamente tiene como resultado un cambio en el tratamiento de dicho caso.

La trascendencia de dicha transformación es palpable también en relación a la invocación del título de legítima defensa para fundamentar la licitud del tiranicidio: puesto que existe esa diferencia que Suárez apunta entre ambos tipos de tirano respecto al momento en que se considera que están infligiendo una violencia que permite entender que el tiranicida está defendiéndose legítimamente (vid. § 13), esto conlleva que el hecho de la posesión o no del título legítimo para gobernar es la regla que determina la aplicación de un criterio u otro. $\mathrm{Y}$, evidentemente, la sentencia de deposición desposee al tirano mal gobernante

7 Esto es así porque o bien la sentencia legitima directamente para la ejecución del tirano, o bien es posible argüir legítima defensa, ya que, si una vez dictada la sentencia, ese rey depuesto continúa en el poder pasa automáticamente a convertirse (como va a explicar Suárez a continuación) en usurpador, y por tanto se entiende que está permanentemente atacando a la comunidad.

8 Suárez retorna aquí nuevamente al primer argumento al mencionar que, puesto que "ya no es ni rey ni soberano legítimo» tampoco "cabe seguir aplicándole a él la declaración [conciliar] que se refiere a los reyes legítimos».

9 La edición del Consejo Superior de Investigaciones Científicas traduce el término "depositionem» a partir de aquí en muchas ocasiones como "destitución». En este caso, como en los siguientes, y pese a la similitud de su significado, hemos preferido mantener el término español directamente derivado de deponere y no el de destituere. 
de su justo título, por lo que desde el momento en que se dicta esa resolución se convierte ipso facto en un usurpador ante el cual es posible en todo momento ejercer la legítima defensa (porque puede ser considerado un permanente agresor de la comunidad) ${ }^{10}$.

\subsection{Aplicación al caso del rey hereje}

Suárez aplica este principio al supuesto del rey hereje, y entiende que en este caso "esta verdad es más clara». Al respecto afirma que el rey hereje

no puede ser privado automáticamente [“ipso facto»] del dominio y propiedad de su reino [...] sino que en justicia sigue poseyéndolo y lo administra legalmente hasta que sea condenado por una sentencia, al menos declarativa, de su crimen.

\section{Ahora bien,}

una vez que se ha dictado sentencia, [al rey depuesto] se le priva por completo de su reino, de modo que ya no pueda con justo título continuar en su posesión.

De modo que

desde ese momento podrá ser tratado absolutamente como un tirano, y en consecuencia podrá ser muerto por cualquier [sujeto] privado.

En cuanto al reino del príncipe condenado, aquel queda "confiscado o pasa por derecho propio a su legítimo sucesor católico» ( $D F, \mathrm{VI}, \mathrm{IV}, 14$,). De nuevo, debe entenderse que el rey hereje depuesto puede ser muerto por cualquier particular precisamente porque a resultas de la sentencia de deposición se ha convertido en un tirano usurpador ${ }^{11}$.

10 Entendemos que Suárez legitima esa actuación del particular en legítima defensa propia de su vida o integridad física precisamente en razón a que queda amparada por el ejercicio de una autoridad pública. Por tanto, de alguna manera, como se verá, junto a la autorización pública expresa, cabría otro tipo de actuación bajo dicho paraguas de la autoridad pública, en este otro caso otorgada y recibida de manera implícita: el supuesto de legítima defensa. Por eso es posible a cualquiera dar muerte al tirano mal gobernante depuesto en sentencia justa y legítima con autoridad pública: no en ejecución de la sentencia (que sólo corresponde a los designados expresamente o a sus sustitutos naturales), sino en ejercicio de la legítima defensa (que, en el caso del usurpador, es siempre alegable).

11 En el mismo sentido, vid. Francisco Tadeo Baciero Ruiz, Poder, ley y sociedad en Suárez y Locke. Un capitulo en la evolucion de la filosofia politica del siglo XVII (Universidad de Salamanca, Salamanca, 2008), 298. Sobre la cuestión de la obediencia a reyes herejes y no cristianos en Francisco Suárez, vid. Pablo Font Oporto, "Obediencia y desobediencia a reyes herejes y no cristianos en Francisco Suárez. Potestad del Papa al respecto", Gregorianum 98, 1 (2017): 61-74. En particular, sobre el tema de la potestad 
2. LA POTESTAD DE DEPOSICIÓN DEL REY: SUJETOS COMPETENTES ( $D F$, VI, IV, 15-17)

\section{De lo anterior concluye lógicamente Suárez que}

puede imponerse la pena de deposición y dictarse sentencia de privación del trono contra un rey, aunque sea soberano en materia temporal ("contra regem supremum etiam in temporalibus").

Ahora bien, nuestro autor reconoce que "es muy discutida la cuestión ["magna questio est»] de quién puede dictar esa sentencia». Para Suárez, en síntesis,

esa potestad de destituir al rey puede darse en la propia comunidad

o en el Papa, aunque de modo diferente ( $D F$, VI, IV, 15).

Y pasa a explicarlo.

\subsection{Potestad de la comunidad política para juzgar y deponer al rey}

Para el jesuita granadino, la potestad de destituir al rey "se da en la comunidad política ["respublica»" ${ }^{12}$ ] únicamente a título de defensa necesaria para su propia conservación» (apunta Suárez que esto ya lo sostuvo en el Libro III—en concreto, en el capítulo III, §3-). De este modo,

si un rey legítimo gobierna tiránicamente y no le queda al reino ningún otro medio de defenderse que expulsar y deponer al rey, podrá la comunidad política en pleno [“respublica tota» ${ }^{13}$ ] por decisión [“consilio»] pública y común de todas sus ciudades y procuradores, deponer al rey.

Las razones que aduce Suárez para legitimar tal capacidad son las siguientes: "primero, en virtud del Derecho natural por el que es lícito repeler la violencia con la violencia» (legítima defensa). En segundo lugar

del Papa para deponer al rey o llevar a cabo acciones equivalentes, vid. ibidem, 68-71.

Por otro lado, debe subrayarse que la mención del supuesto del rey hereje hay que insertarla en el marco del conflicto entre el rey Jacobo I de Inglaterra y el Papa Paulo V.

12 Esta será la traducción que daremos de esta expresión, por entenderla la más adecuada.

13 En este punto concreto seguimos la traducción de Scannone (Scannone, Juan Carlos, "Lo social y lo político según Suárez. Hacia una relectura latinoamericana actual de la filosofía política de Suárez". En Lo político en América Latina. Desafios actuales. Contribución filosófica a un nuevo modo de hacer política, editado por Juan Carlos Scannone y Vicent Santuc, 239-380: 264. Buenos Aires: Bonum, 1999). 
porque este caso, imprescindible para la propia supervivencia de la comunidad política, se considera siempre excluido de aquel primer pacto por el que la comunidad política transfirió su poder al rey ${ }^{14}(D F$, VI, IV, 15).

\subsection{Alcance de la potestad del Papa}

Respecto a la potestad del Papa para juzgar al gobernante, Suárez piensa que en el primero

se da ese poder como en un superior que posee jurisdicción para corregir a los reyes — incluso plenamente soberanos [“reges etiam supremos»]—como a súbditos suyos.

A nuestro juicio, la comprensión de esta y otras afirmaciones debe hacerse en el contexto de la época y del mencionado conflicto del juramento de fidelidad. Desde esta cosmovisión, Suárez reconoce en el Papa poder en materia temporal no sólo indirecto (mediante la excomunión o condena del gobernante por herejía), sino también directo, lo que le permite intervenir para corregir y deponer al gobernante que cometa acciones delictivas en materia espiritual, temporal o que sean "perjudiciales para la comunidad cristiana» $(D F, \mathrm{VI}, \mathrm{IV}, 16)^{15}$.

14 Sobre la necesidad de un acuerdo común del conjunto de la comunidad política, apunta Félix Alluntis una crítica apropiada al constatar que "Suárez supone unas circunstancias políticas en que las ciudades y representantes de la nación pueden reunirse públicamente y dictaminar la sentencia de deposición contra el tirano». Ante esto, se pregunta Alluntis: “¿qué decir de los casos, frecuentes en la historia contemporánea, en que la reunión de representantes del Estado y la sentencia consiguiente es imposible? ¿Habría que declarar al Estado privado del derecho de defensa en tales casos?» (Félix Alluntis, "El tiranicidio según Francisco Suárez", Verdad y vida 88 (1964): 667-682: 676-677, nota 56).

Por otra parte, Pereña Vicente insiste en los vínculos de Suárez con los procuradores en las Cortes de Castilla, y de alguna manera lo relaciona con el movimiento democrático-populista que los mismos intentaron impulsar durante el reinado de Felipe III ( $c f r$. Luciano Pereña Vicente, Pereña Vicente, Luciano. "Perspectiva histórica". En Francisco Suárez. De iuramento fidelitatis. Estudio preliminar: conciencia y política, editado por Luciano Pereña Vicente et al., 15-215: 174-177, 187, 191, 200-202. Madrid: Consejo Superior de Investigaciones Científicas, 1979). En este sentido, para Juan Carlos Scannone, "esa referencia al acuerdo público y común de las ciudades y los próceres, el cual representa el de toda la comunidad política, contiene un embrión de parlamentarismo». Y añade que "de hecho, varios autores (J. N. Figgis, G. Sabine, R. Wilenius) ven en Suárez la fuente no confesada de la teoría de la resistencia sostenida más tarde por los whigs en Inglaterra» (Scannone, "Lo social y lo político", 264). En la misma línea se sitúan Wilenius -Reijo Willenius. The social and political theory of Francisco Suárez (Societas philosophica Fennica: Helsinki, 1963), 82- y Baciero Ruiz, quien sostiene que las teorías suarecianas son empleadas por los whigs contra los tories en el último cuarto del siglo XVII, hasta el punto de que De legibus es publicada íntegramente en Londres en 1679, probablemente a instancias de los primeros (Baciero Ruiz, Poder, 3-4 y 25-39). Scannone puntualiza dicho influjo de Suárez sobre los whigs ingleses sosteniendo que mientras que, por ejemplo, John Locke se mueve dentro de "una concepción individualista del hombre y considera sólo el contrato de gobierno, Suárez, por el contrario, [...] afirma la socialidad [sic] natural del hombre y hace preceder el pacto de asociación al mero pacto de gobierno» (Scannone, "Lo social y lo político", 242 y 264).

15 Algunas de estas cuestiones ya fueron tratadas someramente en Font Oporto, "Obediencia y desobediencia", 68-71. 


\section{Suárez defiende que}

en el caso de crímenes que atañan a materia espiritual, como es el caso de herejía, tiene el Papa el poder directo para castigarlos en el rey, incluso hasta el punto de destronarlo, si así lo exigen la contumacia del rey y el cuidado del bien común de la Iglesia. Pero en el caso de que los delitos atañan a materia temporal, en cuanto que son pecados, pueden también ser corregidos por el poder directo [del Papa]. Y en cuanto pueden ser perjudiciales en el orden temporal para la comunidad política cristiana, podrá castigarlos al menos por su poder indirecto, por el hecho de que el gobierno tiránico de un príncipe temporal es siempre pernicioso para la salvación de las almas ${ }^{16}$ (DF, VI, IV, 16).

a) Sujeción directa de la comunidad política cristiana al Papa en materia concerniente a la defensa frente al tirano y al juicio de deposición del mismo

Es tal el poder que concede Suárez al Papa que llega a hacer depender del mismo la potestad de la comunidad o reino cristiano de defenderse del rey tirano y destituirlo. De este modo, mantiene Suárez que

"si bien la comunidad política o el reino de los hombres-considerado sólo desde el punto de vista de su propia naturaleza, tal y como se dio entre los gentiles y existe actualmente entre los paganos - tiene el poder de defenderse del rey tirano y el de deponerlo en caso de necesidad, sin embargo, los reinos cristianos tienen en este aspecto una cierta dependencia y subordinación respecto del Sumo Pontífice».

El profesor jesuita llega hasta el punto de sostener, en primer lugar, que

el Papa puede ordenar a un reino que no se levante contra su rey sin consultarle ["se inconsulto»] ni lo deponga sin que la causa y razón de ello hayan sido previamente examinadas por el mismo Papa,

en lo que parece un control de legitimidad de la causa de la resistencia ${ }^{17}$.

Más aún, afirma Suárez, en segundo lugar, que el Romano Pontífice

no sólo tiene poder para aconsejar o dar su consentimiento para que el reino deponga al rey que le es perjudicial, sino también para ordenarle y obligarle a

16 En el $\S 3$ del capítulo III del VI de la $D F$ sostiene Suárez que "la sentencia [justa] de deposición dictada por el Papa» contra un rey "bautizado y que hace profesión de cristiano [...] priva eficazmente [al rey] del reino», y además lo hace automáticamente ("ipso facto») ( $D F$, VI, III, 2).

17 La expresión "se inconsulto» no aparece traducida en la versión del Consejo Superior de Investigaciones Científicas. Cabe resaltar que Suárez declara aquí que el Papa "tiene este poder por los peligros mortales y la pérdida de almas que normalmente median en estas revueltas populares y en orden a evitar sediciones y rebeliones injustas» $(D F, \mathrm{VI}, \mathrm{IV}, 17)$. 
que lo haga cuando lo juzgase necesario para la salud espiritual del reino y sobre todo para evitar herejías o cismas.

No sólo eso: para Suárez

entonces es cuando tiene especial aplicación el ejercicio de su poder indirecto sobre los asuntos temporales en orden al fin espiritual y porque en un caso así puede deponer por sí mismo inmediatamente al rey.

Por tanto, "puede [también] forzar al reino a que la lleve a cabo [dicha deposición], si es necesario»» ${ }^{18}(D F, \mathrm{VI}, \mathrm{IV}, 17)$.

b) Breve reflexión sobre el anacronismo de la sujeción del poder temporal de los reyes al poder espiritual del Papa en Suárez

Por lo que concierne a la potestad del Papa, Francisco Belda recuerda que Suárez fundamenta "en la Tradición», "en virtud del poder indirecto de la Iglesia», ese poder pontificio de "deponer al rey que gobierna tiránicamente en un reino cristiano». Hace notar este autor que ese derecho constituye una manera de resolver la dificultad de la ausencia de una jurisdicción superior capaz de 'comisionar' a alguien para que deponga al rey legítimo ${ }^{19}$. Apunta al respecto Rommen que

el derecho del Papa [“a deponer al rey tiránico»] se basa en su poder indirecto sobre los príncipes cristianos y en el antiguo Derecho público positivo, según el cual, en la mayoría de los Estados el príncipe herético y excomulgado perdía su dominio; en cambio, el derecho del pueblo a destronar al tirano se basa en el Derecho natural ${ }^{20}$.

\section{Rommen considera que Suárez}

se apoya en principios de Derecho positivo todavía vigentes en su tiempo (derecho de la Inquisición) o que se deducían de principios jurídicos medievales, como los relacionados con la excomunión y el destierro, que ya no podían imponerse por la fuerza, pero que seguían siendo considerados válidos por canonistas y teólogos 21

18 "Ergo potest cogere regnum, ut id exequatur, si necessarium sit" (DF, VI, IV, 17).

19 Francisco Belda, "Francisco Suárez en el mundo moderno". En Francisco Suárez. De iuramento fidelitatis. Estudio preliminar: conciencia y política, editado por Luciano Pereña Vicente et al., 491-509: 497. Madrid, Consejo Superior de Investigaciones Científicas, 1979.

20 Heinrich Albert Rommen. La teoría del Estado y de la comunidad internacional en Francisco Suárez (Facultad de Derecho y Ciencias Sociales, Instituto de Derecho Internacional: Buenos Aires, 1951), 378.

21 Ibidem, 383. 
En todo caso, es preciso recordar que la cuestión del poder papal de deponer a los gobernantes temporales es un tema discutido desde el inicio del conflicto entre el poder temporal y el espiritual en la Baja Edad Media. De otro lado, parece que la participación (obligada por las circunstancias y forzada por el Cardenal Belarmino) de Suárez en la polémica del juramento de fidelidad a Jacobo I de Inglaterra pudo compeler al profesor granadino (en razón del mandato de la Santa Sede) a adoptar posiciones cercanas a la defensa del poder indirecto del Papa en asuntos temporales ${ }^{22}$. En concreto, en aspectos tales como la potestad del Romano Pontífice para juzgar, condenar y declarar hereje al rey. Esta potestad (en la línea de lo defendido por los otros intervinientes en la disputa que eran favorables al Papado) suponía en la práctica la capacidad por parte del Pontífice de deponer al rey y declarar a sus súbditos libres de la obediencia y fidelidad al mismo, aunque existiese previo juramento al respecto.

Ciertamente pueden observarse aquí residuos de concepciones medievales e hierocráticas, más si cabe teniendo en cuenta el contexto en el que escribe Suárez y el motivo por el que escribe (dentro del conflicto del juramento de fidelidad entre Jacobo I y el Papado, e "invitado» de una manera apremiante por el segundo; adviértase que el propio Suárez señala aquí que sus palabras sobre esta cuestión particular no le van a gustar al rey de Inglaterra). Debe resaltarse, además, que en diferentes pasajes del texto de este juramento de fidelidad impuesto por Jacobo I se rechazaba expresamente (y no sólo en la tercera parte, que es la que recoge Suárez al inicio del capítulo IV, aunque sí aparece más claramente en la misma) la doctrina de la intervención del Papa en asuntos temporales y la supuesta potestad del mismo para privar al rey de su trono y dar licencia para deponerle o inclusive darle muerte (vid. DF, VI, "Proemium», 6). En particular, Suárez critica el juramento establecido por Jacobo I en $D F$, VI, IV, $20-22^{23}$.

22 Vid. L. Pereña Vicente, Perspectiva histórica , 43-44.

23 De otra parte, la postura de Suárez en esta cuestión encaja dentro de la construcción suareciana sobre el tiranicidio legítimo y sus argumentos sobre la autoridad privada y pública y la condición de invasor-agresor del gobernante sin título. Ahora bien, aunque, como ya hemos dicho, las posiciones de Suárez se enmarcan en las defendidas por un bando en un conflicto particular y en un contexto de pensamiento determinado, reducir la doctrina suareciana a simple medievalismo sería reduccionista. 
3. EJECUCIÓN DE LA SENTENCIA DE DEPOSICIÓN Y LEGITIMIDAD DE LA OCCISIÓN DEL TIRANO ( $D F, \mathrm{VI}, \mathrm{IV}, 18$ Y 19)

Suárez hace dos afirmaciones diferentes en las dos primeras frases del primer párrafo del $\S 18$ del capítulo IV a propósito del tirano que ha sido condenado por sentencia justa. La primera frase y afirmación es desarrollada en el resto del $\S 18$ (segundo y tercer párrafo); la segunda frase y afirmación se amplía en el $\S 19$.

3.1. Alcance de la ejecución de la sentencia por parte del juez o su delegado, en especial respecto a la posibilidad de dar muerte al tirano depuesto (análisis de la primera frase de $D F, V I, I V, 18$ y su desarrollo en los párrafos segundo y tercero de dicho $\S)$

a) Supuestos en que es posible dar muerte al rey en ejecución de sentencia

En la primera frase del primer párrafo del $§ 18$ mantiene Suárez que

respecto al último punto propuesto, [...] después de dictarse sentencia condenatoria dada por un poder legítimo por la que el rey es privado de su reino, olo que es igual-después de una sentencia declarativa de un delito que lleva consigo esa pena ipso iure, aquel que dictó la sentencia o la persona a quien éste lo haya encargado, puede privar al rey de su reino, incluso matándolo si no puede hacerlo de otro modo o si aquella sentencia justa alcanza también esa pena.

b) Sujetos legitimados para la ejecución de la sentencia según el autor de la misma (la comunidad política o el Papa)

Si saltamos al segundo párrafo del $\S 18$, apreciamos que para Suárez aquella primera afirmación del $\S 18$ (es decir, la referente a la facultad exclusiva que para la deposición y muerte del rey tiene el autor de la condena o bien aquel que reciba el encargo de éste) "se sigue claramente del principio anterior» (entendemos: del principio que proclama que el gobernante puede ser juzgado por la comunidad o por un superior), porque

quien puede condenar a alguien justamente, puede también llevar a la práctica la pena directamente o poniendo en juego los medios [“auxilia»] necesarios para ello.

A juicio de Suárez, si no fuera así, "vano ["frustra»] sería ese poder de declarar el derecho sin un poder efectivo de coacción». De aquí deriva Suárez que

cuando la comunidad política puede justamente deponer al rey, actúan rectamente sus representantes [“ministri»)] coaccionando al rey o matándolo, si es 
preciso, porque ya no actúan en virtud de una autoridad ["potestate»] privada sino pública ${ }^{24}$.

En el supuesto de que sea el Papa el que dicte la sentencia de destitución del rey, defiende Suárez que, "de igual manera», a este último

sólo podrán expulsarle o matarle aquellos a quienes él [el Papa] se lo encargue. Y si no manda a nadie [en concreto] que ejecute la sentencia, corresponderá a su legítimo sucesor en el reino y, si no existe sucesor, al propio reino ["ad regnum ipsum spectabit»].

Y añade que según la opinión de importantes autores ésta es la manera de proceder en el supuesto del rey hereje, cuando "por pública sentencia se [le] declare $[\ldots]$ privado de su reino» $(D F, \mathrm{VI}, \mathrm{IV}, 18)$.

Por otra parte, en nuestra opinión, del mismo modo corresponderá la ejecución de la sentencia al propio reino en caso de que el legítimo sucesor se desentienda y no la ejecute, si bien este caso parece no preverlo Suárez, o tal vez lo da por sobrentendido ${ }^{25}$.

c) Contradicción entre los requisitos exigidos para la occisión del tirano condenado (en ejecución de la sentencia de deposición) y la legitimación universal para su occisión por parte de cualquier particular (confrontación entre los $\oint_{s} 14$ y 18)

Llegados a este punto conviene subrayar que parece que la exigencia por parte de Suárez de todos estos requisitos para la ejecución de la sentencia de deposición (que eventualmente puede conllevar la occisión del tirano) en $D F$, VI, IV, 18 implica una contradicción con lo afirmado por él mismo en el $\S 14$, donde se sostiene que cualquier particular puede matar legítimamente al tirano sobre el que ha recaído sentencia condenatoria. En concreto, recuérdese que en dicho $\S 14$ sostiene nuestro autor que, en el caso de que la sentencia condene al rey como hereje, éste "podrá ser tratado absolutamente como un tirano y en

24 En el mismo sentido, cita Suárez a Domingo de Soto, quien según el profesor granadino sostuvo que"aunque un individuo cualquiera no puede matar al rey que es tirano sólo en su modo de gobernar [con título legítimo], una vez dictada sentencia, cualquiera - dice - puede ser instituido como encargado de la ejecución [de la sentencia]» $(D F, \mathrm{VI}, \mathrm{IV}, 18)$.

25 A nuestro juicio dicha responsabilidad recae en la comunidad política por varias razones: primera, porque también ésta podría juzgar al rey; segunda, porque le corresponde subsidiariamente; tercera, porque Suárez establece dicha solución un poco más adelante respecto al derecho de declarar la guerra al tirano condenado por el Papa en sentencia de destitución. Quedaría la duda respecto a cuánto tiempo debería la comunidad esperar a la reacción del legítimo sucesor (espera que se antoja necesaria a la luz del pensamiento del profesor granadino); si bien esta duda tampoco la aclara Suárez respecto al caso del derecho de declarar la guerra.26 Nótese, además, que esta afirmación del $\S 14$ se refiere al tirano que originariamente tiene título legítimo, el cual goza del mayor nivel de protección. 
consecuencia podrá ser muerto por cualquier [sujeto] privado $»^{26}$. No parece posible salvar esta contradicción, a no ser que interpretemos que la actuación aceptada en dicho $\S 14$ no se lleva a cabo en ejecución de la sentencia (ejecución que sólo corresponde a los designados expresamente o a sus sustitutos naturales), sino en ejercicio de la legítima defensa.

En efecto, la restricción que Suárez establece en el $§ 18$ sobre las personas que pueden "privar al rey de su reino, incluso matándolo» parece entrar en franca discordancia con la legitimación universal de cualquier particular que el profesor jesuita defiende en el $\S 14$. Recordemos que en este último parágrafo señala Suárez que si ha habido sentencia o mandato de un juez (condenatoria de un delito que implica la deposición), se considera que entonces "se ha esperado a la sentencia justa y legítima» $y$, de este modo se entiende, en primer lugar, que en tal caso al que mata al tirano con autoridad privada no le es aplicable la condena del Concilio de Constanza. Y, en segundo lugar, que dicha persona "no actúa [en realidad] con autoridad privada sino en virtud de la sentencia y, por consiguiente, como instrumento de la autoridad pública». Además, en tercer lugar, la muerte del tirano en este caso puede caber dentro de los supuestos de legítima defensa contra el usurpador, puesto que

si después de su legítima destitución continúa ese rey en su obstinación y por la fuerza retiene el poder real, empieza a ser un tirano con relación a su título, ya que no es rey legítimo ni está en posesión del reino con título justo» ( $D F$, VI, IV, 14).

De modo que la sentencia de deposición del tirano que en principio ostentaba y ejercía el poder con un justo título lo convierte en un usurpador contra el que cabe la legítima defensa en todo caso y aún sin contar (expresamente) con autoridad pública, pues se estima que dicho tirano está agrediendo continuamente a la comunidad y que ésta desea en todo momento ser liberada de dicha agresión, lo que inviste de una autoridad pública en su conducta al que lleva a cabo tal acto de liberación.

Además, Suárez habla en el mencionado $\S 14$ de la posibilidad de dar directamente muerte al tirano, lo que también contradice el mandato del $\S 18$ de que en caso de sentencia de deposición se debe intentar ejecutar la misma sin violencia y sólo darle muerte "si no puede hacerse de otro modo o si aquella sentencia justa alcanza también esa pena" $(D F, \mathrm{VI}, \mathrm{IV}, 18)^{27}$.

26 Nótese, además, que esta afirmación del $\S 14$ se refiere al tirano que originariamente tiene título legítimo, el cual goza del mayor nivel de protección.

27 Por otro lado, cabe destacar que en el $\S 22$ del capítulo VI se afirma que "a un rey que es criminal, aunque se le haya depuesto, no puede en justicia matarlo cualquier individuo del pueblo mediante conjura 
3.2. Inadmisibilidad de la legitimación universal de cualquier particular para repeler o dar muerte al rey depuesto. Análisis de la segunda frase de DF, $V I, I V, 18$

Volvamos ahora a la segunda frase enunciada en el primer párrafo del $\S 18$ del capítulo IV. En la misma Suárez advierte que

el rey depuesto no puede ser muerto inmediatamente ["statim»] por cualquier persona privada, ni siquiera puede ser echado por la fuerza ["per vim repelli»] hasta que no se le ordene así [a esa persona privada, se entiende] o bien se declare una autorización [“commissio»] general de ese tipo en la propia sentencia o en el Derecho ${ }^{28}$.

\section{a) Posibles interpretaciones}

La afirmación contenida en esta frase requiere, a nuestro juicio, ser interpretada. En primer lugar, cabe cuestionarse qué significa "rey depuesto». Una posible interpretación daría a entender que en esta frase Suárez se está refiriendo al caso del monarca tiránico que efectivamente y de hecho ya ha sido apartado del poder (en virtud de una previa pena de deposición dictada por una sentencia justa; como se entiende por el contexto). En este caso, esta segunda frase del primer párrafo del $\S 18$ (que niega la posibilidad de que, como norma general, un particular pueda matar o tan siquiera repeler por la fuerza al rey depuesto), a diferencia de la primera frase de este $\S$ (donde se sostiene que el juez o su delegado sólo pueden dar muerte al rey depuesto si no pueden privarlo del reino de otra forma o bien la sentencia alcanza dicha pena), no estaría en contradicción con lo afirmado en el $\S 14$, pues - conforme a esta interpretación propuesta aquí-lo dicho en este último parágrafo se referiría al tirano que aún detenta el poder $^{29}$. En segundo lugar, de aquí parece seguirse que si, en esta segunda frase del $\S 18$, interpretamos las palabras "rey depuesto» como aquel efectivamente

o asechanza [“insidias»], [...] sino solamente con autoridad pública o en virtud de un poder recibido de quien puede otorgarlo mediante sentencia, o bien por orden o delegación especial» ( $D F, \mathrm{VI}, \mathrm{VI}, 22)$.

28 "Donec ei praecipiatur, vel generalis haec commissio in ipsa sententia vel iure declaratur", la traducción de la edición del Consejo Superior de Investigaciones Científicas ("hasta que no se ordene así en la propia sentencia o en la ley se declare una autorización general de ese tipo») cambia el sentido del texto original. En efecto, Suárez establece que, junto a la autorización o encargo general ["commissio»] emanado de una declaración hecha por la sentencia o por el Derecho, puede haber una orden determinada dirigida a un sujeto privado concreto. Si bien nuestro autor no indica por parte de quién, entendemos que parece que quien puede dar dicha orden es el juez. La traducción del Instituto de Estudios Políticos es también más fiel al texto original: "hasta tanto que se le mande o que en la sentencia o en el derecho se haga ese encargo general».

29 Recuérdese que en este § 14 se afirma que tras la sentencia de deposición justa dictada por juez legítimo cualquiera puede dar muerte al tirano mal gobernante, puesto que le ampara ser instrumento de autoridad pública. 
separado de su trono cabría entender que con las palabras "echado por la fuerza» se está refiriendo Suárez a la expulsión del gobernante no ya del poder, puesto que ya no lo posee, sino fuera del país: es decir, este fragmento aludiría al destierro del rey ya apartado de su trono, lo que no podría ser realizado por cualquiera salvo que así lo dispusiese la propia sentencia o la ley.

De acuerdo con esta interpretación podría entenderse que en el § 14 Suárez se está refiriendo al caso de la occisión del tirano que aún no ha sido apartado del poder y, por tanto, es un tirano mucho más peligroso, ya que conserva todavía todos los resortes del poder. Por tanto, consecuentemente, Suárez concedería a este tirano un tratamiento mucho más severo, pues es preciso despojarlo de dichos resortes, y para esto se requiere una legitimación universal de la actuación de cualquier miembro de la comunidad contra aquel. Ahora bien, conforme a esta interpretación sería fácil comprender que en el $\S 18$ Suárez endurezca extraordinariamente los requisitos de cualquier actuación llevada a cabo contra el tirano una vez que éste ha sido ya apartado del poder, puesto que dicho tirano es mucho menos peligroso y, por tanto, en tal caso deben extremarse las precauciones para que no se desaten venganzas ilegítimas y desproporcionadas por parte de los miembros particulares de la comunidad.

Sin embargo, debe advertirse que de la lectura del $\S 19$, que versa sobre esta segunda frase del $\S 18$, no parece colegirse que pueda interpretarse la expresión "rey depuesto» como aquel que efectivamente y de hecho ya ha sido apartado de su trono, sino que parece más bien que se refiere al tirano que, habiendo sido depuesto formal o nominalmente (es decir, condenado por sentencia justa de deposición), sigue de hecho detentando efectivamente el poder ${ }^{30}$. Por tanto, esta frase, al igual que la anterior, se estaría refiriendo también a la ejecución de la

30 Consideramos procedente transcribir aquí dicho $\S 19$, sobre el que volveremos más abajo. En el mismo afirma Suárez: "[...] aun cuando uno haya sido justamente condenado a muerte, no puede matarlo cualquier [persona] privada por propia iniciativa, salvo que se lo ordene quien tiene autoridad o tenga otra razón para hacerlo, ya que nadie puede matar a otro si no es el superior que tiene en sí mismo poder para ello o bien su representante» $(D F, \mathrm{VI}, \mathrm{IV}, 19)$.

Ahora bien, para ser considerado representante es preciso actuar por mandato de la autoridad principal. Y añade Suárez que "si esto es verdad respecto a cualquier delincuente, con mayor razón sin duda tiene aplicación respecto del príncipe. Tal vez alguno diga que basta el primer impulso implícito o tácito de la comunidad política, que por el hecho mismo de haber depuesto al rey quiere que todos lo expulsen, coaccionen e incluso lo maten si se resiste. Pero esto es una falsedad y pura ficción contraria a la razón. Porque el juez que condena a una persona privada por hereje o delincuente no concede automáticamente a todo el mundo la facultad de actuar contra él. Luego tampoco la comunidad política ni el Papa, al condenar a un rey hereje o tirano por otro concepto, conceden esa autorización a todos, ni siquiera tácita o implícitamente. Por ninguna razón justa cabe presumir tal autorización contra el príncipe en mayor medida que contra otras personas. Siempre es, en efecto, necesaria la prudencia y una justa medida en la ejecución de la sentencia y existe un mayor peligro de desórdenes y excesos al coaccionar la persona de un príncipe o rey que cuando se trata de otros individuos. [...]» $(D F, \mathrm{VI}, \mathrm{IV}, 19)$. 
sentencia de deposición del rey tirano. Como consecuencia, si nos atenemos a esta interpretación y entendemos que la segunda frase se refiere al gobernante que aún permanece en el poder, parece que no cabría entender que las palabras "echado por la fuerza» aludan al destierro del gobernante fuera del país $(D F, \mathrm{VI}$, IV, 18).

b) Gradación en la ejecución de la sentencia de deposición, sujetos ejecutores competentes y legitimación del tiranicidio en los supuestos más graves. Comparación entre las dos primeras frases de $\mathrm{DF}, \mathrm{VI}, \mathrm{IV}, 18$

Si se comparan las dos primeras frases del $\S 18$, cabe advertir que existen sustanciales diferencias en el tratamiento del tema de los sujetos competentes para la ejecución de la sentencia. Esas diferencias comportan una gradación en la posibilidad de la occisión del monarca.

Conviene notar que en la primera frase Suárez sostiene que, existiendo una sentencia que dispone la deposición del monarca (o, lo que entendemos que es lo mismo, privación de su reino), o que conlleva dicha sanción, esta resolución debe ser ejecutada, bien por aquel que la dictó, o bien por la persona a quien dicho juez "lo haya encargado». Al respecto, el profesor jesuita advierte que en este caso dicha destitución sólo puede conllevar la occisión del tirano únicamente en dos supuestos: primero, que no pueda ejecutarse la sentencia de deposición de otro modo; segundo, que en dicha sentencia esté contemplada también esa pena de muerte.

En la segunda frase del $\S 18$ Suárez trata el supuesto en que un sujeto privado cualquiera (por tanto, no expresamente comisionado) pretende dar muerte o deponer al tirano que ha sido condenado por sentencia justa de deposición. Al respecto, se estipula que no sólo ningún particular está legitimado para dar muerte directa e inmediatamente a dicho tirano, sino que tampoco puede apartarlo del trono por la fuerza. Cabe, sin embargo, una excepción a esta regla general: sería legítima la actuación directa contra el tirano depuesto por parte de cualquier particular (en términos de expulsión por la fuerza del poder o incluso de occisión ${ }^{31}$ ) cuando exista un encargo o autorización general emanado, bien de la propia sentencia condenatoria, bien del Derecho.

Ahora bien, si lo entendemos así, parece que, en lo que respecta a las posibilidades de actuación contra el monarca depuesto, las facultades que legítimamente pueden ejercerse por parte del sujeto expresamente comisionado son

31 Tal vez por la expresión que utiliza Suárez, "inmo neque per vim repelli» ("ni tampoco» alejar por la fuerza») parece que sólo se permitiría a los particulares, en esos casos excepcionales, el acto de expulsarlo. Sin embargo, la presencia de una coma hace dudar al respecto. 
obviamente mayores que las que se reconocen a cualquier sujeto privado. Sin embargo, es posible apreciar que detrás de esta diferencia existe también una gradación más profunda que sólo es posible apreciar interpretando a contrario lo afirmado por Suárez en esta segunda frase.

En efecto, si bien en la primera se defiende que el sujeto comisionado puede dar muerte al tirano cuando no puede deponerlo de otra manera, o bien cuando la sentencia condenatoria incluye dicha pena, en la segunda se abre la puerta a la posibilidad de permitir (bien en la propia sentencia, bien mediante una autorización general declarada en una ley) que cualquier sujeto privado (no expresamente comisionado) dé muerte legítimamente al monarca depuesto. De tal modo que, conforme a la segunda frase (y en oposición a la primera), cualquier particular podría no sólo ejercer la fuerza contra el tirano para deponerlo efectivamente sino incluso darle muerte. Por lo tanto, parece que si bien en general sólo es lícita la ejecución de la sentencia de deposición del tirano (y, en su caso, la occisión del mismo) por parte de los sujetos expresamente comisionados para ello, en ciertos casos especialmente graves o perentorios ${ }^{32}$ se hace necesario legitimar la actuación de cualquier sujeto privado no sólo para repeler sino incluso para dar muerte al tirano depuesto (ya se conceda esta facultad en la propia sentencia condenatoria o mediante autorización general).

\subsection{Limites en la legitimación implícita para ejecución de la sentencia: DF,} VI, IV, 19. Justificación de la segunda frase del § 18

Como ya adelantamos, en el $\S 19$ Suárez pasa precisamente a justificar la segunda frase del $\S 18$. El profesor jesuita mantiene que

32 Cabría cuestionarse si esta posibilidad se abriría también en aquellos casos en que (existiendo por supuesto la autorización necesaria en la propia sentencia o en la ley), y a pesar de existir alguien comisionado expresamente para la ejecución de la sentencia, dicho comisionado no pudiera llevar a término el encargo judicial. El problema que se plantearía en caso de admitirse este supuesto sería que, a priori, en tal caso parece que cualquier sujeto privado tendría menores limitaciones para la ejecución de la sentencia que el propio comisionado, ya que las limitaciones que Suárez impone a este para poder darle muerte (que no pueda privarlo del reino de otro modo o que la sentencia alcance dicha pena) no las reproduce cuando habla de la autorización a cualquier particular. Si bien es verdad también que esta posible contradicción podría resolverse entendiendo que en este último supuesto las limitaciones que aparecen en el primero se darían por sobrentendidas, nos inclinamos más bien a considerar que Suárez no contempló este supuesto en que, existiendo un comisionado expreso, se legitimaría a cualquier particular en vista de la imposibilidad de que este ejecutara la sentencia. Lo cual queda reforzado en la lógica que subyace al requisito de que dicha autorización general debe estar prevista en la propia sentencia o en la ley. En este sentido, la autorización universal no significaría probablemente una facultad subsidiaria respecto a los comisionados expresos, sino que se estimaría más procedente la inexistencia de los mismos debido a las circunstancias existentes y se optaría por tanto por legitimar la actuación de cualquier particular (en última instancia, y propiamente hablando, el tiranicidio). 
aun cuando uno haya sido justamente condenado a muerte, no puede matarlo ${ }^{33}$ cualquier [persona] privada por propia iniciativa, salvo que se lo ordene quien tiene autoridad [la edición del CSIC añade "para ello»] o tenga otra razón para hacerlo ["vel aliter moveatur»] ya que nadie puede matar a otro si no es el superior que tiene en sí mismo poder para ello o bien su representante.

Suárez puntualiza que "nadie puede ser llamado su representante si no actúa a impulso de la autoridad principal». Y concluye: "si esto es verdad respecto a cualquier malhechor, con mayor razón sin duda tiene aplicación respecto del príncipe».

\section{Advierte Suárez que}

tal vez alguno diga que basta el primer impulso implícito o tácito de la comunidad política, que por el hecho mismo de haber depuesto al rey quiere que todos lo expulsen ["expelli»], coaccionen e incluso lo maten si se resiste».

Nuestro autor es contrario a esta opinión, y señala que del mismo modo que el juez que condena a una persona privada por hereje o delincuente no concede automáticamente a todo el mundo la facultad de actuar contra él, [...] tampoco la comunidad política ni el Papa, al condenar a un rey hereje o tirano por otro concepto, conceden esa autorización a todos, ni siquiera tácita o implícitamente.

Y agrega Suárez que "por ninguna razón justa cabe presumir tal autorización contra el príncipe en mayor medida que contra otras personas». De modo que si "siempre es, en efecto, necesaria la prudencia y una justa medida ["iustus modus» ${ }^{34}$ ] en la ejecución de la sentencia», debe tenerse presente que "existe un mayor peligro de desórdenes y excesos al coaccionar la persona de un príncipe o rey que cuando se trata de otros individuos» $(D F, \mathrm{VI}, \mathrm{IV}, 19)$.

De igual modo, volviendo al caso de sentencia dictada por el Papa, Suárez considera al respecto que si mediante la misma declara éste

que un rey es hereje y queda privado del reino, y no hace ninguna ulterior declaración sobre la ejecución de la misma, no por eso cualquier príncipe puede emprender la guerra contra él sin más [“statim»].

33 "Non potest [...] illum occidere»; la edición del Consejo Superior de Investigaciones Científicas traduce "no puede ser ejecutado por"».

34 Hemos preferido esta traducción, en la línea de la edición del del Instituto de Estudios Políticos (que traslada "moderación»), antes que la de la edición del Consejo Superior de Investigaciones Científicas (que traduce como "procedimiento justo»). 
Porque, en efecto, no es este otro monarca "de superior categoría en el orden temporal, ni ha sido investido por el Papa, en virtud sólo de su sentencia, con ese poder [de emprender la guerra contra el otro príncipe]» (eso sí, Suárez reconoce expresamente al Papa la potestad de encargar de forma manifiesta la ejecución de la sentencia al gobernante de otro país; véase un poco más abajo).

Prosigue el profesor granadino afirmando que, en efecto, ese poder (de emprender la guerra contra el tirano condenado por el Papa, en el caso de que éste no encargue específicamente a alguien la ejecución de la sentencia) únicamente lo tiene-como ya defendió antes Suárez-el "legítimo sucesor, si es católico, [...] o, en el caso de que éste se desentienda de ello o no exista [tal sucesor]", será "la comunidad del reino, siempre que sea católica» la que "le sucederá en este derecho». Es decir, al igual que la comunidad política puede juzgar al rey, puede emprender contra él la guerra, aunque parece que tiene prioridad el legítimo sucesor ${ }^{35}$. Caso distinto es el de que esa comunidad del reino pida ayuda a otros príncipes, en cuyo caso "podrán prestársela, como es evidente». Del mismo modo, en el supuesto de que el Papa "otorgue a los otros reyes poder para invadir aquel reino, en ese caso pueden hacerlo legítimamente, porque no les falta justa causa ni autoridad ["potestas»] [la edición del CSIC añade "necesaria»]» $(D F, \mathrm{VI}, \mathrm{IV}, 19)$.

\section{RECAPITULACIÓN DE LAS IDEAS DE SUÁREZ SOBRE EL ENJUI- CIAMIENTO, DEPOSICIÓN Y OCCISIÓN DEL TIRANO EN DF, VI, IV, 14-19}

A modo de resumen de las ideas recogidas en el segundo apartado, cabe apuntar que para Suárez el tirano mal gobernante puede ser depuesto mediante sentencia justa y legítima, en cuyo caso puede dársele muerte con autoridad pública a título de legítima defensa. Para nuestro autor la potestad de deponer al

35 Como ya adelantamos, no queda claro cuánto debe esperar la comunidad para ver cuál es la reacción de dicho legítimo sucesor. Es éste otro punto un tanto oscuro.

Respecto al derecho del legítimo sucesor católico de emprender justa guerra, coincide con el derecho que le corresponde de hacer ejecutar la sentencia de deposición dictada por el Papa si éste no se lo manda a nadie en concreto (véase el $\S 18$, donde, por otro lado, no se exigía expresamente que el sucesor fuera católico). Esto derechos del legítimo sucesor son lógicos teniendo en cuenta que, como se afirma en el $\S$ 14, el reino del príncipe condenado queda "confiscado o pasa por derecho propio a su legítimo sucesor católico» (DF, VI, IV, 14 y 18).

Por otra parte, Suárez deja sin resolver la cuestión de qué sucedería en caso de que la comunidad no fuera católica, suponiendo que la sentencia condenatoria no señalase a nadie concreto como encargado de la ejecución ni existiese sucesor legítimo o éste se desentendiese (se da por supuesto que para Suárez en este caso al menos el tirano debería ser católico, de otro modo para nuestro autor no tendría potestad el Papa sobre el mismo, como sostiene en otros pasajes; vid. infra). 
rey puede darse en la propia comunidad o en el Papa, aunque en supuestos y sobre fundamentos diferentes.

En el caso de la comunidad, dicha potestad existe únicamente a título de defensa necesaria para su propia conservación, por lo que es una posibilidad a la que nunca puede renunciar la propia comunidad. Por otra parte, en el contexto de la época y del conflicto del juramento de fidelidad, Suárez reconoce al Papa poder en materia temporal, tanto indirecto como directo. En el supuesto de que sea el Romano Pontífice el que dicte la sentencia de deposición del rey, la ejecución de la misma sólo corresponde a quien que se le haya encomendado; en su defecto al legítimo sucesor del rey depuesto, y en última instancia al propio reino. Estos dos últimos sujetos deberán ser católicos para poder llevar a cabo dicha ejecución. De otro lado, la deposición de un soberano por el Papa no significa una autorización general para que otros príncipes le declaren la guerra.

Por lo que respecta a la ejecución de la sentencia dictada por la comunidad política, el juez o los que han recibido por mandato expreso el encargo de dicha ejecución pueden apartar efectivamente al tirano del poder, y para ello podrían si fuera preciso emplear la fuerza o incluso darle muerte. Igualmente podrían hacerlo si se recoge expresamente esa posibilidad en la orden, mandato o sentencia. Los particulares no comisionados expresamente no sólo no pueden dar muerte al tirano condenado, sino tampoco emplear la fuerza contra él, salvo que así se estableciese en la sentencia o bien en una autorización general mediante ley.

\section{CONCLUSIONES}

Suárez concede un tratamiento especial al tirano que ha sido objeto de un juicio y condena de deposición dictada por juez legítimo. Dicho tratamiento supone que se amplían las posibilidades de dar muerte a dicho tirano condenado, si bien existen ciertas contradicciones en su teoría respecto a la viabilidad que dicha condena abre respecto a las posibilidades de ampliación de la legitimidad del tiranicidio. En todo caso, parece que, propiamente hablando, el Doctor Eximio entiende que la ejecución de la sentencia (que puede conllevar, en determinadas circunstancias la muerte del tirano condenado) debe corresponder a priori al que la dictó o a aquellos en que el mismo delegue.

En el marco de la época, para Suárez la legitimidad para el enjuiciamiento de dicho tirano recae bien en la propia comunidad política, bien en el Papado, a quien reconoce una especie de potestad arbitral sobre los reyes temporales cristianos. Esto último ha sido criticado en la literatura científica contemporánea, 
pero cabe advertir que ese papel encaja en la cosmovisión de la época (ampliamente compartida por Suárez), y la no comprensión de esto puede dar lugar a anacronismos en el análisis de estas cuestiones. Por no hablar de que, probablemente, en esta cuestión (como en las demás que hemos revisado en este trabajo) Suárez da probablemente pruebas, una vez más, de poseer un agudo sentido de la facticidad, esto es, de la persecución de las soluciones más apegadas a la realidad ${ }^{36}$.

\section{REFERENCIAS BIBLIOGRÁFICAS}

\section{A. FUENTES DIRECTAS O PRIMARIAS}

Suárez, Francisco. Defensio fidei catholicae et apostolicae adversus anglicanae sectae errores, cum responsione ad apologiam pro iuramento fidelitatis et praefationem monitoriam serenissimi Iacobi Angliae regis. Conimbricae: apud Didacum Gomez de Loureyro academiae typographum, 1613.

Edición manejada del Libro III de la Defensio fidei:

Suárez, Francisco. Defensio fidei III: Principatus politicus o la soberanía popular. Madrid: CSIC,1965.

Ediciones manejadas del Libro VI de la Defensio fidei:

Suárez, Francisco. De Iuramento Fidelitatis. Documentación fundamental. Madrid: CSIC, 1978.

- Defensa de la fe católica y apostólica contra los errores del anglicanismo, t. 4/4, Madrid: Instituto de Estudios Políticos, 1971.

\section{B. FUENTES INDIRECTAS O SECUNDARIAS}

Alluntis, Félix. "El tiranicidio según Francisco Suárez". Verdad y vida 88 (1964): 667-82.

36 Sobre la cuestión de la facticidad suareciana vid. Font Oporto, El derecho de resistencia, 8, 155160, 180-186; Font Oporto, "El núcleo"; Font Oporto, Límites de la legitimidad; Pablo Font Oporto, "La facticidad de la filosofía política de Francisco Suárez: un camino hacia otra Modernidad", Pensamiento: Pensamiento: Revista de investigación e información filosófica 74, 279 (2017): 179-200; Pablo Font Oporto, El enfoque politico pragmático-fáctico de Francisco Suárez. De las soluciones ideológicas modernas al bien común concreto y no institucional, en Simposio UNIJES de Pensamiento Social Cristiano "Propuestas en tiempos de crisis". Actas Electrónicas (Sevilla: Universidad Loyola Andalucía, 2013), pp. 55-58. Consultado el 11 de agosto de 2019. https:/www.uloyola.es/investigacion/departamentos/humani dades-y-filosofia/simposio-unijes 
Baciero Ruiz, Francisco Tadeo. Poder, ley y sociedad en Suárez y Locke: Un capitulo en la evolucion de la filosofía politica del siglo XVII. Salamanca: Universidad de Salamanca, 2008.

Belda, Francisco. "Francisco Suárez en el mundo moderno". En Francisco Suárez. De iuramento fidelitatis. Estudio preliminar: conciencia y política, editado por Luciano Pereña Vicente et al., 491-509. Madrid: Consejo Superior de Investigaciones Científicas, 1979.

Font Oporto, Pablo. El derecho de resistencia civil en Francisco Suárez. Virtualidades actuales. Granada: Comares, 2018.

—. "La facticidad de la filosofía política de Francisco Suárez: un camino hacia otra Modernidad". Pensamiento: Pensamiento: Revista de investigación e información filosófica 74, 279 (2017): 179-200.

- "Obediencia y desobediencia a reyes herejes y no cristianos en Francisco Suárez. Potestad del Papa al respecto". Gregorianum 98 (2017): 61-74.

-. "Tipos de tirano y resistencia en Francisco Suárez". Anales de la Cátedra Francisco Suárez 51 (2017): 183-207.

—. "Límites de la legitimidad del poder político y resistencia civil en Francisco Suárez" (PhD diss., Universidad de Sevilla, 2014). Consultado el 11 de agosto 2019. https://idus.us.es/xmlui/handle/1 1441/70443

—. "El núcleo de la doctrina de Francisco Suárez sobre la resistencia y el tiranicidio". Pensamiento: Revista de investigación e información filosófica 69 (2013): 493-521.

—. "El enfoque político pragmático-fáctico de Francisco Suárez: de las soluciones ideológicas modernas al bien común concreto y no institucional", en Simposio UNIJES de Pensamiento Social Cristiano "Propuestas en tiempos de crisis". Actas Electrónicas, Sevilla: Universidad Loyola Andalucía, 2013, pp. 55-58. Consultado el 11 de agosto de 2019. https://www.uloyola.es/investigacion/departamentos/humanidades-y-filosofia/simposio-unijes

Pereña Vicente, Luciano. "Perspectiva histórica". En Francisco Suárez. De iuramento fidelitatis. Estudio preliminar: conciencia y política. Editado por Luciano Pereña Vicente et al., 15-215. Madrid: Consejo Superior de Investigaciones Científicas, 1979.

Rommen, Heinrich Albert. La teoría del Estado y de la comunidad internacional en Francisco Suárez. Buenos Aires: Facultad de Derecho y Ciencias Sociales, Instituto de Derecho Internacional, 1951.

Scannone, Juan Carlos. "Lo social y lo político según Suárez. Hacia una relectura latinoamericana actual de la filosofía política de Suárez". En Lo político 
en América Latina. Desafios actuales. Contribución filosófica a un nuevo modo de hacer politica. Editado por Juan Carlos Scannone y Vicent Santuc, 239-380. Buenos Aires: Bonum, 1999.

Willenius, Reijo. The social and political theory of Francisco Suárez. Helsinki: Akateeminen kirjakauppa 1963.

\section{Pablo Font Oporto}

Departamento/Facultad de Humanidades y Filosofía Universidad Loyola Andalucía Parque de Investigación y Desarrollo Dehesa de Valme Avda. de las Universidades, $\mathrm{s} / \mathrm{n}$ 41704 Dos Hermanas (Sevilla). https://orcid.org/0000-0002-7446-0275 
